\title{
Screening differential expression of serum proteins in AFP-negative HBV-related hepatocellular carcinoma using iTRAQ -MALDI-MS/MS
}

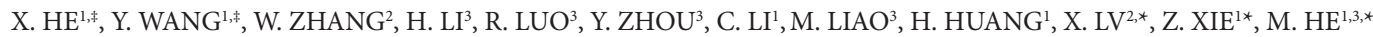 \\ ${ }^{1}$ Public Health School of Guangxi Medical University, Nanning 530021, China; ${ }^{2}$ The First Affiliated Hospital of Guangxi Medical University, \\ Nanning 530022, China; ${ }^{3}$ Medical Scientific Research Center of Guangxi Medical University, Nanning 530021, China
}

*Correspondence: $m \_h \_m 868 @$ sina.com, zhichunxie@yahoo.com

${ }^{*}$ Contributed equally to this work.

Received February 4, 2013 / Accepted April 26, 2013

\begin{abstract}
Hepatocellular carcinoma (HCC) is serious condition associated with a high morbidity and mortality. Therefore is an urgent need to develop novel noninvasive techniques for early diagnosis, particularly for patients with AFP-negative [AFP(-)] HCC. In this study, iTRAQ-MALDI-MS/MS was used to identify differentially expressed proteins in AFP(-) HBV-related HCC compared with non-cancerous hepatitis B virus (HBV) and healthy controls subjects.

Serum was obtained from 18 patients with AFP(-) HBV-related HCC, 18 matched patients with HBV without HCC and 18 healthy control subjects. High abundance proteins were removed from serum and the differentially expressed proteins from the three groups were screened out using iTRAQ-MALDI-MS/MS. The Gene Ontology (GO) function and the interaction networks of differentially expressed proteins were then analyzed.

A total of 24 expressed differential proteins associated with AFP(-) HBV-related HCC were screened out, 15 proteins were up-regulated and 9 down-regulated. The most common molecular function of the 24 differentially expressed proteins was enzyme inhibition. Interaction network of the 24 differentially expressed proteins showed that 14 proteins (C5, KNG1, FN1, LRG1, HRG, SERPINC1, CRP, APOB, SAA1, APCS, C4BPA, CFI, CFB and GSN) were central to the functional network. The expression levels of the GSN protein were down-regulated in AFP(-) HBV-related HCC subjects compared with healthy controls and the HBV group $(\mathrm{p}<0.01)$, consistent with the iTRAQ results.

The 14 proteins from the serum of AFP(-) HBV-related HCC appeared at the fulcrum of the functional network and were differentially expressed compare to HBV and healthy controls suggesting a possible association with HCC progression.
\end{abstract}

Key words: HCC, AFP Negative, iTRAQ, GSN

Primary HCC is one of the six most common cancers in the world. In 2008, the World Health Organization estimated 750,000 new cases of HCC and 695,900 deaths due to the disease, of which half occurred in China [1]. Patients with chronic $\mathrm{HBV}$ are at greater risk of developing HCC. More than $50 \%$ of HCC cases worldwide and $70-80 \%$ of HCC cases in $\mathrm{HBV}$ endemic regions are attributable to $\mathrm{HBV}$. Survival rates of HBV-related HCC range from $36 \%$ to $67 \%$ after 1 year and from $15 \%$ to $26 \%$ after 5 year of diagnosis [2]. However, patients treated for early HCC lesions can have high survival rates $[3,4]$, emphasizing the need for early diagnosis and accurate staging of patients with HCC.

At present, the diagnosis of HCC relies on serological markers, such as alpha fetoprotein (AFP) together with serological liver function tests, pathological assessment and imaging techniques [5]. Liver biopsy is routinely considered as the gold standard method of staging HCC, but has disadvantages such as patient unwillingness, morbidity and sampling errors [6]. In addition, the sensitivity of AFP is less accurate in persons with chronic active hepatitis $\mathrm{B}$ and hepatitis C [7]. Moreover in early stage HCC, small lesions less than $3 \mathrm{~cm}$, have increased AFP levels $(<20 \mathrm{ng} / \mathrm{mL})$ in only $20-30 \%$ of cases [8] however, this percentage is continually falling with the development of better imaging techniques. We defined this group as having AFP-Negative hepatocellular carcinoma [9]. According to previous studies, approximately $40 \%$ of early HCC patients and 15-20\% with advanced HCC patients are AFP-Negative [10]. In China, data has shown that $30-40 \%$ of patients with HCC are AFP-negative [11]. These discrepancies highlight the need for the development of novel 
non-invasive techniques for diagnosis of HCC, especially for cases who are $\operatorname{AFP}(-)$.

Serological detection is widely regarded as the best choice for disease screening because of its ease of use and advantages that include detection of both physiological and pathological conditions. However, detection and quantification of serological markers is challenging due to their complexity and diversity [12]. The efficient depletion of high abundance proteins prior to proteomic analysis is proven as an ideal method for detecting expression changes of less abundant proteins [13]. In these reports, the Agilent Multiple Affinity Removal System (MARS) was proven to be reproducible and reliable for the depletion of 14 most prevalent high abundance proteins from human serum $[14,15]$.

Currently, iTRAQ (isobaric tags for the relative and absolute quantization) reagent is widely applied to differentiate expressed proteins in comparative proteomics due to largescale, high throughput and highly sensitivity procedures [16, 17]. The iTRAQ technique identifies amino groups by using specific, isotope-code tags labelled peptides and tandem mass spectrometry analysis, stemmed from Applied Biosystems Inc (ABI) [18]. This technique is able to compare the relative levels of the same proteins from eight different samples simultaneously.

In this study, liquid chromatography (LC) and tandem MS were combined with iTRAQ to quantitatively compare serum samples from patients with AFP(-) HBV-related HCC, HBV without HCC and healthy control subjects. Fourteen proteins were delineated that might be significantly associated with AFP(-) HBV-related HCC.

\section{Materials and methods}

Serum samples. Serum samples were collected between 2009 and 2011 from patients attending the Affiliated Hospital of Guangxi Medical University, Nanning, China. All samples were officially registered and all patients gave informed consent. A total of 20 patients with HBV-related HCC were AFP(-). Patients with other hepatitis virus infections (HAV, HCV, HEV), with other liver diseases or previously treated with antivirals, were excluded from the study. AFP(-) HCC was diagnosed histologically according to the Barcelona criteria
[19] and patients with AFP values less than $20 \mathrm{ng} / \mathrm{mL}$ were included in the study. All patients with chronic HBV infection were confirmed by positive HBsAg serology.

Fasting blood samples from patients with AFP(-) HBV-related HCC, age and gender matched HBV patients and healthy control subjects were collected in serum separation tubes. The tubes were centrifuged for $10 \mathrm{~min}$ at $4000 \mathrm{~g}$ within 30-120 min after being collected. Then sera from the three groups were pooled ( $\mathrm{n}=10$ patients/group) and stored in frozen plastic vials at $-80^{\circ} \mathrm{C}$ until analysis. Detailed information of the blood samples are shown in Table 1.

High abundance protein depletion. The 14 highest abundance proteins were extracted from serum at room temperature with Agilent 1200 HPLC system (Agilent Technologies, Waldron, Germany) and installed with MARS Human 14 (4.6 mm id $\times 100 \mathrm{~mm}$, Agilent Technologies, Inc.). Prior to injection into the MARS columns, the pooled serum samples from each group were diluted three times with Buffer A (Agilent Technologies, Inc.), transferred to a $0.22 \mu \mathrm{m}$ spin filter and centrifuged for one minute at $16,000 \mathrm{~g}$ to remove particles. After collection of the less abundant protein fractions, the MARS columns were washed and the bound proteins were eluted with $100 \%$ buffer B (Agilent Technologies, Inc.). Procedures were conducted according to the protocol supplied by the manufacturer.

Desalted and protein content estimation. The less abundant protein fractions were concentrated and desalted using 3000 MWCO Hydrosart Vivaspin 2 spin concentrators (Sartorius Stedim Biotech, Gottingen, Germany), centrifuged (Eppendorf 5810R, Germany) at $5000 \mathrm{~g}$ and at $4^{\circ} \mathrm{C}$, which was repeated three times. On each occasion, the sample solution was buffer exchanged with $50 \mathrm{mM}$ triethylammonium bicarbonate (TEAB, pH 8.5 buffer, Sigma-Aldrich Corporation, Saint Louis, MO, USA). The concentrated samples were determined using Nanodrop 2000 (Thermo Scientific, USA) and samples from each group were normalized to pack at $100 \mu \mathrm{g} / \mathrm{tube}$ and dried.

Protein digestion and peptide iTRAQ labeling. Each tube, containing $100 \mu \mathrm{g}$ of dried low abundant proteins, was digested and labeled using chemicals in the 8-plex iTRAQ reagent kit (ABI, Framingham, MA) and 8-plex iTRAQ buffer kits (ABI, Framingham, MA) according to manufacturer's instructions.

Table 1. Sample data

\begin{tabular}{|c|c|c|c|c|c|c|c|}
\hline & \multirow[t]{2}{*}{ Group } & \multirow[t]{2}{*}{$\mathrm{n}$} & \multirow[t]{2}{*}{$\operatorname{Sex}(M / F)$} & \multicolumn{4}{|c|}{ Mean \pm SD } \\
\hline & & & & Age & $\operatorname{AFP}(\mathrm{ng} / \mathrm{mL})$ & $\operatorname{ALT}(\mathrm{IU} / \mathrm{L})$ & AST (IU/L) \\
\hline \multirow[t]{3}{*}{1} & HCC & 10 & $10 / 0$ & $55.20 \pm 10.73$ & $11.22 \pm 6.03$ & $83.11 \pm 92.58$ & $121.56 \pm 155.61$ \\
\hline & $\mathrm{HBV}$ & 10 & $10 / 0$ & $53.40 \pm 9.68$ & $(-)$ & $329.67 \pm 153.48$ & $309.35 \pm 201.60$ \\
\hline & Control & 10 & $10 / 0$ & $55.30 \pm 10.25$ & $(-)$ & $(-)$ & $(-)$ \\
\hline \multirow[t]{3}{*}{2} & HCC & 8 & $8 / 0$ & $56.20 \pm 10.78$ & $14.37 \pm 5.04$ & $95.45 \pm 70.23$ & $117.68 \pm 123.74$ \\
\hline & HBV & 8 & $8 / 0$ & $54.50 \pm 7.89$ & $(-)$ & $201.50 \pm 180.24$ & $324.13 \pm 327.27$ \\
\hline & Control & 8 & $8 / 0$ & $55.86 \pm 10.26$ & $(-)$ & $(-)$ & $(-)$ \\
\hline
\end{tabular}

Group1: iTRAQ-LC-MS/MS, Group 2:western blotting, (-): Negative 


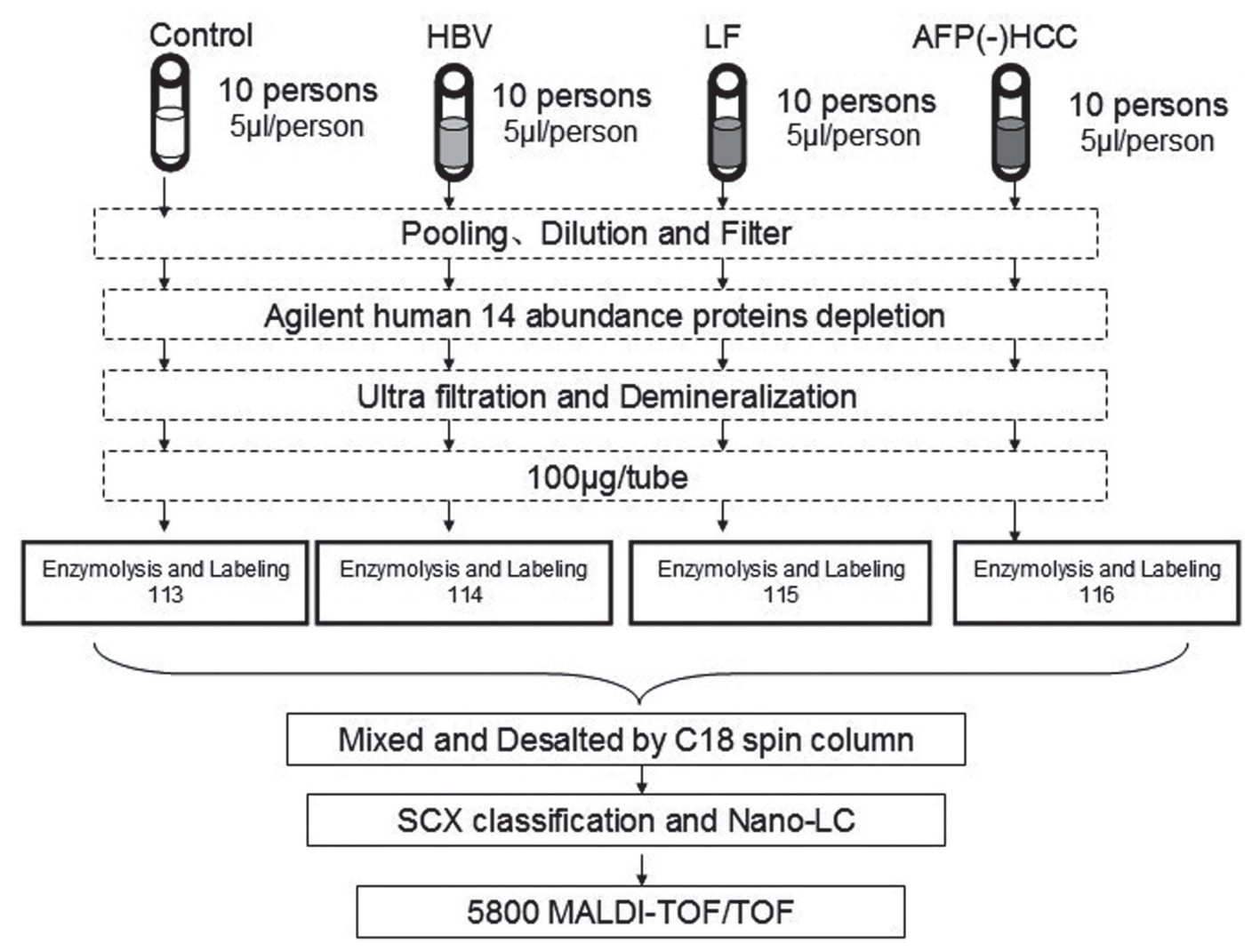

Figure 1. Study flow chart. The serum samples of each group were pooled from 10 persons with $5 \mu \mathrm{L}$ from each person, diluted three-times and transferred to a spin filter to remove particles, depleted 14 highest abundance proteins using Agilent Human 14 MARS columns, desalted and normalized at $100 \mu \mathrm{g} /$ group, digested and labeled with iTRAQ reagents, mixed and desalted, fractioned using SCX, spotted on a Tempo LC and analyzed on 5800 MALDI-TOF/TOF Analyzer.

Briefly, the dried low abundant proteins were dissolved at $5 \mathrm{mg} / \mathrm{mL}$ in $0.5 \mathrm{M}$ TEAB, and denatured by $1 \mu \mathrm{L} 2 \% \mathrm{SDS}$. Then, the proteins were reduced for one hour at $60^{\circ} \mathrm{C}$ with $5 \mathrm{mM}$ tris-(2-carboxyethyl) phosphine (TCEP), cysteine-blocked for 10 minutes with $10 \mathrm{mM}$ methyl methanethiosulfonate (MMTS) at room temperature and digested for 12 to 16 hours at $37^{\circ} \mathrm{C}$ in the presence of $10 \mu \mathrm{L}$ of $0.5 \mu \mathrm{g} / \mu \mathrm{L}$ trypsin. Each resulting peptide solution was identified for two hours at room temperature using an iTRAQ reagent previously reconstituted in $50 \mu \mathrm{L}$ of isopropanol. The reaction was terminated by adding $100 \mu \mathrm{L}$ of milliQ water to the samples. The healthy control, $\mathrm{HBV}$ and the AFP(-) HBV-related HCC samples were labeled with iTRAQ as 113,114 and 116 respectively. For the parallel study, 115 and 114 were labeled as the same samples, then combined in one tube and desalted using a C18 spin column (Nest Group Inc, USA), and dried again.

Strong cation exchange chromatography (SCX) and nano-LC separation. The dried peptides were dissolved with $10 \mathrm{mM} \mathrm{KH}_{2} \mathrm{PO}_{4}$ and 25\% CAN at $\mathrm{pH} 2.7$, fractionated with strong cation exchange chromatography (SCX) on a $2.1 \times 200 \mathrm{~mm}$ polysulfoethyl column (PolyLC, Columbia, MD). The SCX Buffer B contained $500 \mathrm{mM} \mathrm{KCl}, 10 \mathrm{mM}$
$\mathrm{KH}_{2} \mathrm{PO}_{4}$, and $25 \% \mathrm{ACN}$ at $\mathrm{pH}$ 2.7. The SCX gradient lasted for 110 minutes with Buffer B changing from $0 \%$ to $100 \%$ at 25 minutes to 95 minutes then peptide fractions were collected at two minute intervals, then dried. Each SCX fraction was further separated by reverse phase nanoflow LC, performed on a Tempo LC MALDI Spotting system (ABI-MDS/Sciex) using a Chromolith CapRod column (150 x $0.1 \mathrm{~mm}$, Merck). The fractions were spotted directly onto a MALDI sample plate (1664 spots per plate, Applied Biosystems). Tempo Buffer A was $2 \%(\mathrm{v} / \mathrm{v})$ acetonitrile (ACN) and $0.1 \%(\mathrm{v} / \mathrm{v})$ trifluoroacetic acid (TFA), and Tempo Buffer B was 98\% acetonitrile and $0.1 \%$ trifluoroacetic acid. Each SCX dried fraction was re-suspended in $40 \mu \mathrm{L}$ Tempo Buffer A. The gradient elution lasted for 50 minutes, Buffer B changed from 0 to $80 \%$ at 4 to 42 minutes. The HPLC eluent was spotted automatically onto the MALDI plates in a $44 \times 28$ spot array format.

MALDI-MS/MS and database searching. MS and MS/MS analyses of offline spotted peptide samples were performed using the 5800 MALDI-TOF/TOF Analyser (Applied Biosystems). Glu-1 fibrinopeptide at m/z 1570.677 diluted in the matrix ( $\alpha$-Cyano-4-hydroxycinnamic acid (CHCA)) was used for internal calibration. MS spectra were acquired 
from 900 to $4000 \mathrm{~m} / \mathrm{z}$, for a total of 1500 laser shots. Laser intensity remained fixed throughout the analyses. MS/MS analyses were performed using at a collision energy of $2 \mathrm{kV}$ with air at $2 \times 10^{-6}$ Torr as the collision gas. Metastable ions were suppressed, for a total of 1500 laser shots. Twenty of the most intense ion signals, characterized by an $\mathrm{S} / \mathrm{N}>$ 45 , were automatically selected as precursors for MS/MS acquisition.

Protein identification and quantification were performed with ProteinPilot ${ }^{\mathrm{TM}} 4.0$ software (version 4.0; Applied Biosystems, USA), with novel Paragon ${ }^{\mathrm{TM}}$ database. The search parameters were set as follows: Homo sapiens, trypsin cleavage, Cysteine alkylation by MMTS. Each MS/MS spectrum was searched against the uniprot database. Proteins having at least one peptide above the $95 \%$ confidence level (unused ProtScore C 1.3) were recorded.

Choosing differentially expressed proteins. The expression of differential proteins of HCC compared with healthy controls and the $\mathrm{HBV}$ without HCC group were separated by the time of mass spectrometry under the following criteria: at least two peptides with distinct sequences identified in MS/MS analysis, unused ProtScore $>1.3, p<0.05$, the values of $116 / 113$ in the ranges of $>1.2$ or $<0.8$ and the values of $116 / 114$ were in the ranges of $>1.2$ or $<0.8$. The iTRAQ ratios below 0.8 were considered to be under-expressed, whereas those above 1.2 were considered to be over-expressed.

Data analysis. The functions of the differentially expressed proteins were classified into categories using the database described at http://david.abcc.ncifcrf.gov/. An interaction diagram was produced for the differentially expressed proteins using the database described at www.string-db.org.

Western blotting. Western blotting was performed as previously described [20]. The primary antibody, mouse antihuman monoclonal antibody, was used at a concentration of 1:350 (Santa Cruz,USA), the secondary antibody was IRDye-labeled goat anti-mouse (LI-COR, USA), and used at a concentration of 1:5000 and quantitative analysis were performed using Odyssey (LI-COR, USA).

Table 2. The differentially expressed proteins in AFP(-) HBV-related HCC

\begin{tabular}{|c|c|c|c|c|c|c|c|c|c|}
\hline Expression & Number & Accession & Name & $\begin{array}{c}\text { Pval } \\
(116: 113)\end{array}$ & Mean & $\begin{array}{c}\text { 116:113 } \\
\text { Lower CI }\end{array}$ & Upper CI & 116:114 & 116:115 \\
\hline up-regulated & 1 & P02741 & $\mathrm{C}$-reactive protein $(\mathrm{CRP})$ & 0.0003 & 33.1131 & 12.5892 & 86.2979 & 8.9536 & 9.2462 \\
\hline in $\mathrm{HCC}$ & 2 & P68871 & Hemoglobin subunit beta (HBB) & 0.0191 & 14.0605 & 5.7544 & 36.9828 & 2.582277 & 2.47729 \\
\hline compare to & 3 & P02735 & Serum amyloid A protein (SAA1) & 0.0002 & 14.0605 & 5.2966 & 46.1318 & 34.35255 & 28.58861 \\
\hline healthy & 4 & P01011 & Alpha-1-antichymotrypsin (SERPINA3) & 0.0005 & 10.5682 & 3.4356 & 25.3513 & 7.943029 & 7.22325 \\
\hline \multirow[t]{11}{*}{ control } & 5 & P02750 & Leucine-rich alpha-2-glycoprotein (LRG1) & 0.0000 & 7.5162 & 2.6303 & 36.9828 & 3.531883 & 3.158805 \\
\hline & 6 & P10643 & Complement component C7 (C7) & 0.0015 & 5.2481 & 2.4889 & 11.5878 & 0.43652 & 0.405509 \\
\hline & 7 & P04003 & C4b-binding protein alpha chain (C4BPA) & 0.0055 & 3.8019 & 1.7378 & 27.5423 & 1.659566 & 1.254993 \\
\hline & 8 & Q06033 & $\begin{array}{l}\text { Inter-alpha-trypsin inhibitor heavy chain } \\
\text { H3 (ITIH3) }\end{array}$ & 0.0003 & 3.281 & 2.0701 & 17.8649 & 1.870688 & 2.019056 \\
\hline & 9 & P02748 & Complement component C9 (C9) & 0.0000 & 3.0479 & 1.7701 & 12.7057 & 2.754292 & 3.018239 \\
\hline & 10 & P01042 & Kininogen-1 (KNG1) & 0.0324 & 2.704 & 1.3804 & 3.5975 & 0.619445 & 0.731147 \\
\hline & 11 & P01834 & Ig kappa chain C region (IGKC) & 0.0367 & 2.355 & 1.1272 & 7.6560 & 0.691813 & 0.4355 \\
\hline & 12 & P01031 & Complement C5 (C5) & 0.0000 & 2.2284 & 1.4723 & 8.3176 & 1.753817 & 2.16994 \\
\hline & 13 & P00751 & Complement factor B (CFB) & 0.0122 & 2.0701 & 1.4723 & 2.5586 & 1.527524 & 1.786358 \\
\hline & 14 & P04114 & Apolipoprotein B-100 (APOB) & 0.0000 & 1.9953 & 1.5996 & 2.4434 & 1.786463 & 2.013827 \\
\hline & 15 & P05156 & Complement factor I (CFI) & 0.0338 & 1.9409 & 1.1482 & 6.7298 & 1.690385 & 1.598838 \\
\hline down-regulated & 1 & P05546 & Heparin cofactor 2 (SERPIND1) & 0.0179 & 0.7178 & 0.5861 & 0.8472 & 1.458943 & 1.645429 \\
\hline in HCC & 2 & $\mathrm{P} 02743$ & Serum amyloid P-component (APCS) & 0.0121 & 0.4966 & 0.2754 & 0.7447 & 2.249094 & 2.547332 \\
\hline compare to & 3 & P04196 & Histidine-rich glycoprotein (HRG) & 0.0000 & 0.4875 & 0.1706 & 0.6668 & 0.501182 & 0.51116 \\
\hline \multirow[t]{6}{*}{$\begin{array}{l}\text { healthy } \\
\text { control }\end{array}$} & 4 & P19823 & $\begin{array}{l}\text { Inter-alpha-trypsin inhibitor heavy chain } \\
\text { H2 (ITIH2) }\end{array}$ & 0.0002 & 0.4831 & 0.1923 & 0.7516 & 0.376745 & 0.410922 \\
\hline & 5 & P01008 & Antithrombin-III (SERPINC1) & 0.0121 & 0.4246 & 0.2168 & 0.6982 & 0.608135 & 0.44385 \\
\hline & 6 & P02751 & Fibronectin (FN1) & 0.0000 & 0.3981 & 0.2128 & 0.5495 & 0.270393 & 0.301196 \\
\hline & 7 & P06727 & Apolipoprotein A-IV (APOA4) & 0.0000 & 0.3802 & 0.2291 & 0.5754 & 0.373257 & 0.453772 \\
\hline & 8 & Q9UGM5 & Fetuin-B (FETUB) & 0.0192 & 0.1941 & 0.0437 & 0.8630 & 0.158501 & 0.114524 \\
\hline & 9 & P06396 & Gelsolin (GSN) & 0.0001 & 0.1528 & 0.0711 & 0.4966 & 0.131861 & 0.108677 \\
\hline
\end{tabular}

113: Healthy controls, 114: HBV, 115:HBV (parallel ), 116: AFP(-) HBV-related HCC 
A

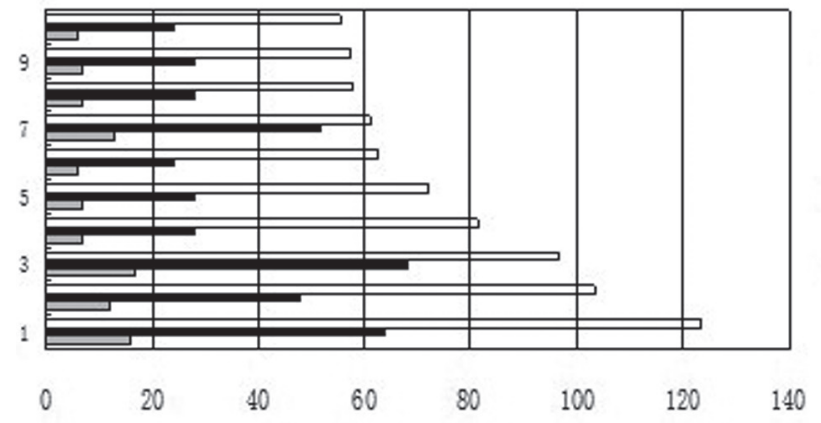

B

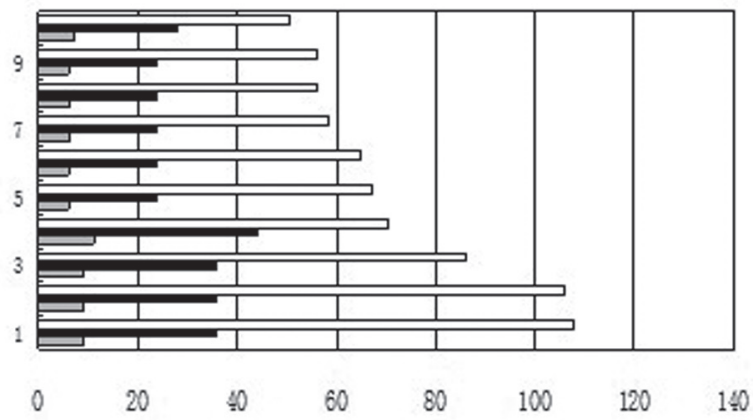

C

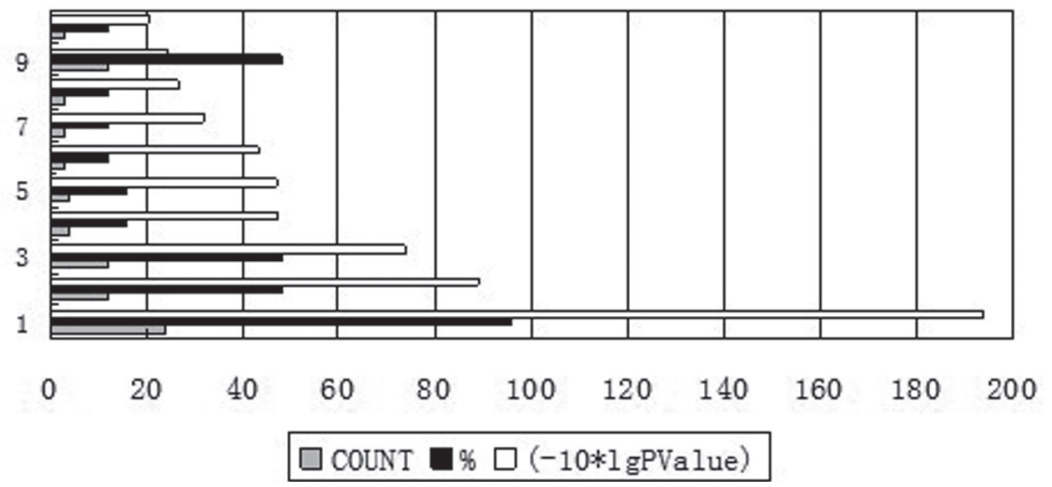

Figure 2. The Gene ontology (GO) annotation figure of differentially expressed proteins in AFP(-) HBV-related HCC. The greater the values of X-axis units, the more the number of clustered proteins and the greater the credibility of function. (A) Biology process: 1, response to external stimulus. 2 , regulation of response to stimulus. 3 , response to stress. 4 , activation of immune response. 5 , immune effector process. 6, coagulation. 7 , regulation of biological quality. 8 , positive regulation of response to stimulus. 9, positive regulation of immune system process. 10, regulation of body fluid levels. (B) Molecular function:1, endopeptidase inhibitor activity. 2, peptidase inhibitor activity. 3, enzyme inhibitor activity. 4, enzyme regulator activity. 5, serinetype endopeptidase inhibitor activity. 6, heparin binding. 7, glycosaminoglycan binding. 8, pattern binding. 9, polysaccharide binding. 10, carbohydrate binding. (C) Cellular component: 1, extracellular region. 2, extracellular space. 3, extracellular region part. 4, plasma lipoprotein particle. 5, protein-lipid complex. 6, membrane attack complex. 7, high-density lipoprotein particle. 8, vesicle lumen. 9, macromolecular complex. 10, pore complex.

\section{Results}

Differentially expression proteins. A total of 271 proteins matched the mass spectra identification conditions, identified with software on the 5800 MALDI-TOF/TOF Analyzer. A total of 24 differentially expressed proteins in AFP(-) HBV-related HCC sera using the criteria of differentially expressed protein, were identified from the 271 proteins. The expression levels of 15 proteins were up-regulated in samples in patients with AFP(-) HBV-related HCC and 9 were down-regulated. In a parallel test, two same pooled HBV samples were labeled with 114 and 115 respectively. There was no significant different between the values of $116 / 114$ and $116 / 115(t=0.13$, $\mathrm{p}>0.05$ ). (Table 2).

Functional classification and interaction of differentially expressed proteins. The functional classification of the 24 differentially expressed proteins are shown in Figure 2. The most common Biology Process were 'response to external stimulus' and ' response to stress', and the most common Cellular Component was 'extracellular region', the more common Molecular Functions were 'endopeptidase inhibitor activity', 'peptidase inhibitor activity' and 'enzyme inhibitor activity'. An interaction diagram was produced for the 24 differentially expressed proteins using the database described at www.string-db.org (Figure 3). Proteins C5, KNG1, FN1, LRG1, HRG, SERPINC1, CRP, APOB, SAA1, APCS, C4BPA, CFI, CFB and GSN appeared in the center of the functional network intersection indicating their important role in the protein interactions.

Western blotting. One of the differentially expressed proteins identified as GSN is showed in Figure 4. GSN was not only at the center of the functional network intersection, but also at the lowest expression level of the 24 differentially expressed proteins. Therefore, GSN was selected for a validation test. In Western blotting, the expression level of GSN in AFP(-) HBV-related HCC was significantly lower than for the healthy 


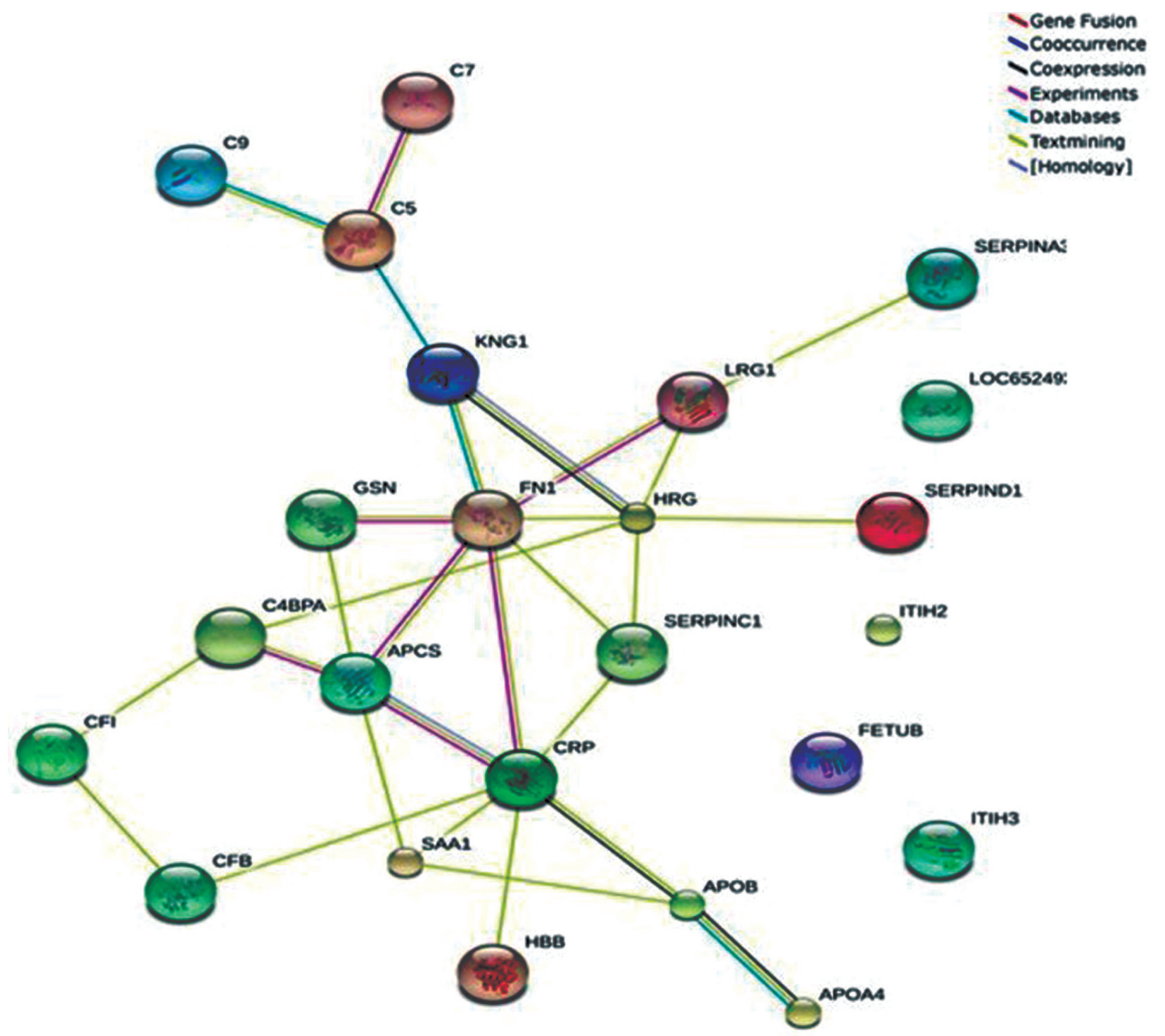

Figure 3. Interaction diagram of 24 differentially expressed proteins in AFP(-) related HCC. http://www.string-db.org/newstring_cgi/show_ network_section.pl. Proteins C5, KNG1, FN1, LRG1, HRG, SERPINC1, CRP, APOB, SAA1, APCS, C4BPA, CFI, CFB and GSN appeared in the center of the functional network intersection

controls and the HBV group ( $<<0.01$, Figure 5). This result was consistent with iTRAQ-LC- MS/MS consequence.

\section{Discussion}

The focus of current proteomics research is the identification of differentially expressed proteins. iTRAQ-MS/MS is more sensitive, has higher protein sequence coverage and good reproducibility compared with ICAT-MS/MS and 2D-DIGE $[21,22]$. In this study, we screened 24 proteins that demonstrated differential expression in AFP(-) HBV-related HCC using iTRAQ-MALDI-MS/MS.

Of the 24 screened differentially expressed proteins, 15 proteins were up-regulated in AFP(-) HBV-related HCC and 9 proteins were down-regulated. Among them, 9 proteins (SERPIND1, SERPINC1, KNG, CFB, CFI, C5, C7, C9 and $\mathrm{C} 4 \mathrm{BPA})$ were involved in the complement and coagulation cascade pathway, which is closely related to cancer development [23, 24]. A total of 14 proteins (C5, KNG1, FN1, LRG1,
HRG, SERPINC1, CRP, APOB, SAA1, APCS, C4BPA, CFI, CFB and GSN) appeared in the center of the functional network intersection and warrant further study.

FN1 (Fibronectin) is believed to have a role in cell adhesion, cell motility, opsonization, wound healing, and maintenance of cell shape [25], however, its physiological role is not fully understood. Altered fibronectin expression, degradation, and organization is associated with a number of different pathologies, including fibrosis and cancer development. FN1 was shown to be a direct target gene for miR-1 and is negatively regulated by miR-1. While miR- 1 may play a role as a tumor suppressor gene in laryngeal carcinoma [26], Zhao et al, [27] reported that levels of FN mRNA expression were markedly decreased or even absent in poorly and moderately differentiated HCC cells. It was therefore concluded that FN1 protein is significantly down-regulated in $\operatorname{AFP}(-)$ HCC.

KNG1(Kininogen-1) is an inhibitor of thiol proteases [28] and acts early in the intrinsic pathway of coagulation. Its 

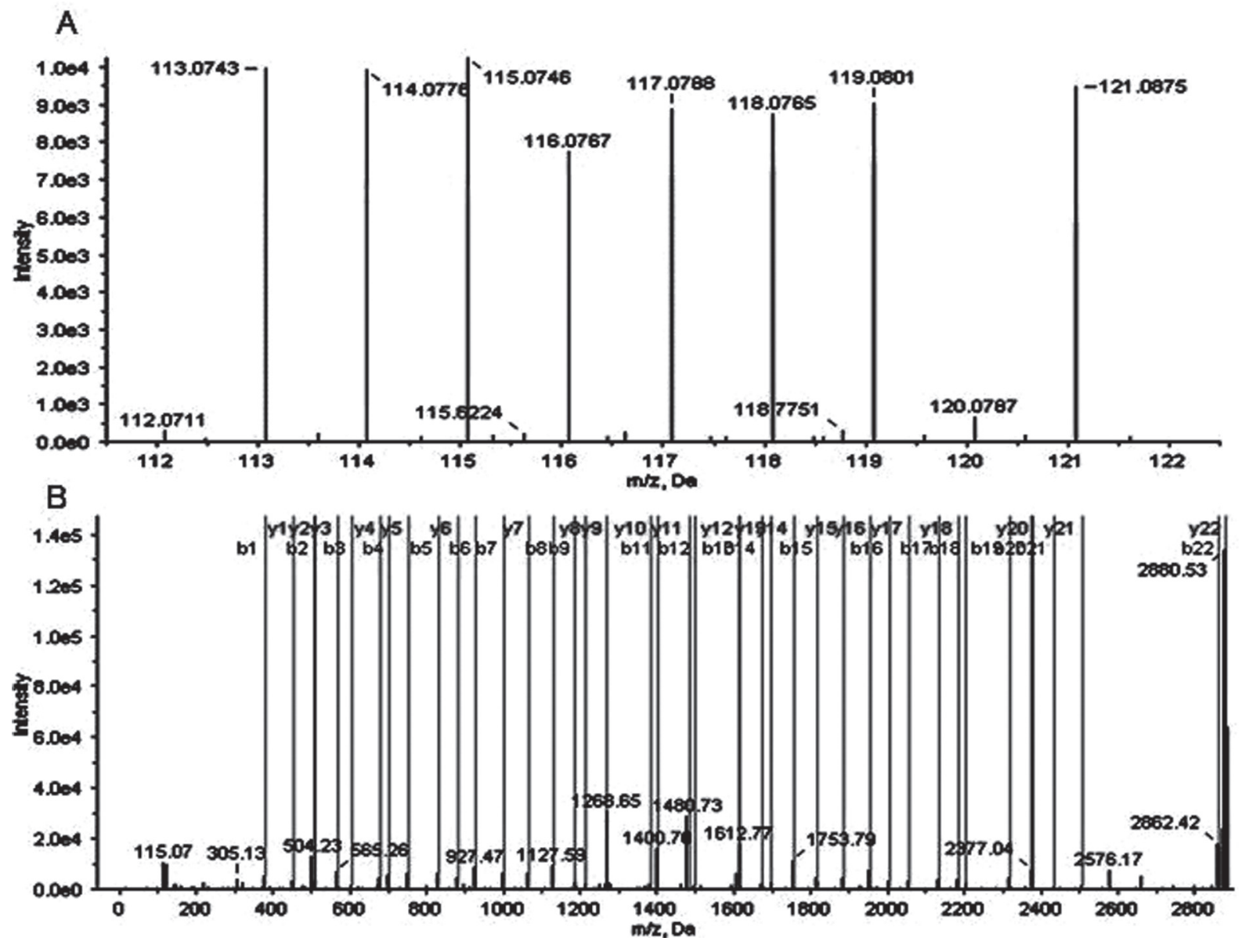

Figure 4. The identification of the peptide AQPVQVAEGSEPDGFWEALGGK of GSN by MS/MS. A. Quantitative information for peptide. B. The peptide fragments, including b-ion and y-ion series. The peptide digests in healthy control group, HBV group, HBV (parallel) and AFP(-) HBV-related HCC group were labeled with iTRAQ-113, 114, 115 and 116 tags.

function in the activation pathway includes smooth muscle contraction, natriuresis, diuresis, inflammatory response and positive regulation of apoptosis and KNG1 plays an essential role in prevention of metastasis of cancer cells. Additionally, KNG1 is significantly up-regulated in irradiated mice [29] and this may translate to up-regulation of KNG1 when the human body is exposed to various carcinogenic factors.

LRG1 (leucine-rich alpha-2-glycoprotein) is a protein upstream of the TGF- $\beta$ R II pathway, but its function remains largely unknown, although increased expression has been shown in many cancers. One study suggested a potential use in the diagnosis of bladder cancer, as increased levels were reported in the urine [30]. In another study, high levels were found in biliary tract cancer compared with cholangiocytes in benign biliary disease [31].

Moreover, some of the 14 proteins were shown to be closely related to HCC and considered as biomarker candidates in the detection of early HCC. HRG (histidine-rich glycoprotein) is known as an abundant and well-characterized protein in vertebrate plasma [32]. It can bind plasminogen, fibrinogen, and thrombospondin and although the physiologic role is unknown, it is reported to be relevant in some cancers [33, 34]. In a study by Liu et al, HRG, C3, CE, CD14 and HGF were considered as biomarker candidates for the detection of early HCC [35]. C-reactive protein (CRP) is an acute-phase reactant that is frequently raised in patients with liver disease [36]. Elevated CRP is associated with a poor prognosis in patients with HCC and may be a useful marker for treatment selection [37]. Serum levels of SAA1 (Serum amyloid A protein), an acute phase reactant, are elevated in response to trauma, infection, inflammation and neoplasia. Elevated levels in patients with cancer is thought to be of liver origin rather than from tumor cells [38]. Shu et al, reported, that five important differential proteins (HP, Hp2, preprohaptoglobin, SP40 and SAA1) can lead to the detection of HCC at an earlier stage in addition to surveillance of HCC in patients with cirrhosis [39].

GSN (Human plasma gelsolin), an intracellular actin-binding protein, is functionally involved in cell shape changes, cell 
A

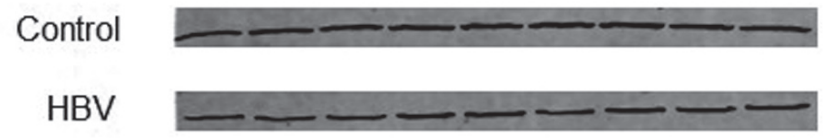

AFP(-) HCC

B

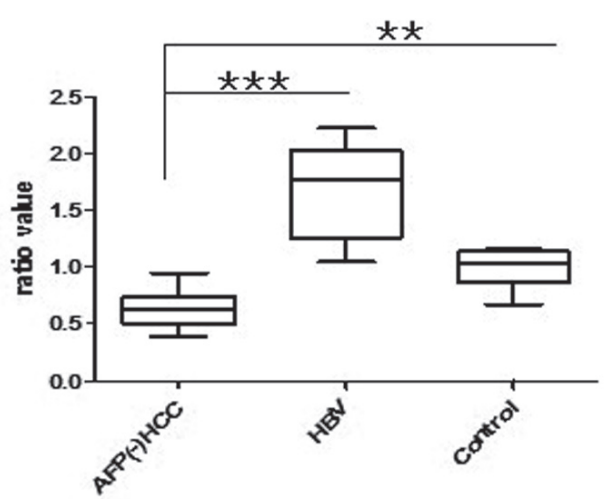

Figure 5. Western blotting detected of GSN. A, The expression of GSN in healthy controls, HBV and AFP(-) HBV-related HCC group. Each serum sample contained $50 \mu \mathrm{g}$ proteins. All first columns were the same internal controls pooled with all samples. $B$, The results of Western blotting revealed that GSN was significantly down-regulated in AFP(-) $\mathrm{HBV}$-related HCC, ${ }^{* * *}(\mathbf{p}<0.001),{ }^{* *}(\mathbf{p}<0.01)$. The ratio value $=$ sample $/$ internal control.

motility and apoptosis by binding to actin, calcium ions and proteins. It is implicated in two distinct pathways: amyloids and organism-specific biosystem and can act as both an effector and an inhibitor of caspase- 3 and other membrane phospholipids, to regulate the onset and progression of apoptosis [40]. It is postulated that GSN may bind to p53 and thereby inhibit p53-induced apoptosis by anchoring p53 in the cytoplasm in HepG2 cells [41]. It is therefore probable that low levels of expression of GSN in AFP(-) HBV-related HCC may be associated with apoptosis. Expression of the GSN gene is a known down-regulated target in breast cancer and other tumors [42]. In previous studies, 6 proteins (ORM1, GSN, C9, HABP2, SAA2, and C3) were used as a sensitive, non-invasive diagnostic test to estimate the probability of developing colorectal cancer [43]. In the present study, the Western blotting results demonstrate that expression of GSN in AFP(-) HCC was significantly reduced compared with healthy controls and the HBV group without HCC $(\mathrm{p}<0.01)$, consistent with iTRAQ-LC- MS/MS consequences. We conclude, that serum GSN is down-regulated in patients with $\operatorname{AFP}(-)$ HBV-related HCC.

The other 10 proteins that appeared in the periphery of the functional network have been implicated in patients with cancer and are worthy of further research. For example, SERPINA3 was found to be up-regulated in HLA-positive tumors [44]. The IGKC was validated as an immunologic biomarker of prognosis and response to therapy in human breast cancer and other cancers [45]. FETUB may potentially be useful for the treatment of diseases characterized by excess angiogenesis [46]. ITIH2 was found to show frequent down regulation that may be associated with initiation and/or progression of some malignancies [47]. Thus far, ITIH molecules have been shown to play a particularly important role in inflammation and carcinogenesis, but ITIH2 and ITIH3 may play different roles in the progression of cancer and present different levels of expression. In contrast to ITIH2, ITIH3 protein was found in to be highly expressed in plasma of tumor bearing mice and the authors suggested it may be a useful biomarker for the early detection of gastric cancer ${ }^{[48]}$. These variations were supported in our own experiments.

\section{Conclusion}

The search for simple, sensitive and specific biomarkers to facilitate the diagnosis of HCC, particularly for patients with $\operatorname{AFP}(-)$ HCC, is of great significance for early diagnosis and early treatment. The results from this study suggest that the expression of 14 proteins (C5, KNG1, FN1, LRG1, HRG, SERPINC1, CRP, APOB, SAA1, APCS, C4BPA, CFI, CFB and GSN), in the serum of AFP(-) HBV-related HCC were different compared with the serum of healthy controls and the HBV group. These 14 differentially expressed proteins might be highly associated with the progression of AFP(-) HBV-related HCC.

Acknowledgements: This research was supported by the National Natural Science Foundation of China, (Nos. 81260445,30960332 and 30460121); Innovaive Research Team of Intellectual Highland in High School of Guangxi (Guijiaoren[2010]38); Guangxi Scientific Research and Technological Development Foundation (No 0993003C-13) and the Open Fund of Medical Scientific Research Center of Guangxi Medical University (No. KFJJ2010-45).

\section{References}

[1] FERLAY J, SHIN HR, BRAY F, FORMAN D, MATHERS C, et al. Estimates of worldwide burden of cancer in 2008: GLOBOCAN 2008. Int J Cancer. 2010; 127: 2893-917. http://dx.doi. org/10.1002/ijc.25516

[2] NGUYEN VT, LAW MG, DORE GJ. Hepatitis B-related hepatocellular carcinoma: epidemiological characteristics and disease burden. J Viral Hepat. 2009; 16: 453-63. http://dx.doi. org/10.1111/j.1365-2893.2009.01117.x

[3] SHERMAN M. Hepatocellular carcinoma: epidemiology, surveillance, and diagnosis. Semin Liver Dis. 2010; 30: 3-16. http://dx.doi.org/10.1055/s-0030-1247128

[4] TANG ZY, YU YQ, ZHOU XD, MA ZC, YANG BH, et al. Analysis of one hundred and twenty five patients with primary liver cancer surviving more than five years. Gan To Kagaku Ryoho.1992; 19: 1202-6. 
[5] CATURELLI E, BARTOLUCCI F, BIASINI E, VIGLIOTTI ML, ANDRIULLI A, et al. Diagnosis of liver nodules observed in chronic liver disease patients during ultrasound screening for early detection of hepatocellular carcinoma. Am J Gastroenterol. 2002; 97: 397-405. http://dx.doi.org/10.1111/ j.1572-0241.2002.05477.x

[6] ALVAREZ D, ANDERS M, MELLA J, AMANTE M, OROZCO F, et al. [Usefulness of transient elastography (Fibroscan(R)) in the assessment of fibrosis in patients with chronic liver disease]. Medicina (B Aires). 2012; 72: 10-4. 7 El-Aneed A, Banoub J. Proteomics in the diagnosis of hepatocellular carcinoma: focus on high risk hepatitis B and C patients. Anticancer Res. 2006; 26: 3293-300.

[8] ZHANG G, HA SA, KIM HK, YOO J, KIM S, et al. Combined analysis of AFP and HCCR-1 as an useful serological marker for small hepatocellular carcinoma: a prospective cohort study. Dis Markers. 2012; 32: 265-71. http://dx.doi. org/10.1155/2012/964036

[9] XU J, LIU C, ZHOU L, TIAN F, TAI MH, et al. Distinctions between clinicopathological factors and prognosis of alphafetoprotein negative and positive hepatocelluar carcinoma patients. Asian Pac J Cancer Prev. 2012; 13: 559-62. http:// dx.doi.org/10.7314/APJCP.2012.13.2.559

[10] MARINGHINI A, COTTONE M, SCIARRINO E, MARCENO MP, LA SETA F, et al. Ultrasonography and alpha-fetoprotein in diagnosis of hepatocellular carcinoma in cirrhosis. Dig Dis Sci. 1988; 33: 47-51. http://dx.doi. org/10.1007/BF01536630

[11] LOK AS, LAI CL. alpha-Fetoprotein monitoring in Chinese patients with chronic hepatitis $B$ virus infection: role in the early detection of hepatocellular carcinoma. Hepatology. 1989; 9: 110-5. http://dx.doi.org/10.1002/ hep. 1840090119

[12] CARR SA, ANDERSON L. Protein quantitation through targeted mass spectrometry: the way out of biomarker purgatory? Clin Chem. 2008; 54: 1749-52. http://dx.doi.org/10.1373/ clinchem.2008.114686

[13] AVASARALA JR, WALL MR, WOLFE GM. A distinctive molecular signature of multiple sclerosis derived from MALDI-TOF/MS and serum proteomic pattern analysis: detection of three biomarkers. J Mol Neurosci. 2005; 25: 119-25. http://dx.doi.org/10.1385/JMN:25:1:119

[14] DRAKE PM, SCHILLING B, NILES RK, BRATEN M, JOHANSEN E, et al. A lectin affinity workflow targeting glycosite-specific, cancer-related carbohydrate structures in trypsin-digested human plasma. Anal Biochem. 2011; 408; 71-85. http://dx.doi.org/10.1016/j.ab.2010.08.010

[15] SHORES KS, KNAPP DR. Assessment approach for evaluating high abundance protein depletion methods for cerebrospinal fluid (CSF) proteomic analysis. J Proteome Res. 2007; 6: 3739-51. http://dx.doi.org/10.1021/pr070293w

[16] LATTERICH M, ABRAMOVITZ M, LEYLAND-JONES B. Proteomics: new technologies and clinical applications. Eur J Cancer. 2008; 44: 2737-41. http://dx.doi.org/10.1016/ j.ejca.2008.09.007

[17] CHEN X, SUN L, YU Y, XUE Y, YANG P. Amino acid-coded tagging approaches in quantitative proteomics. Expert Rev
Proteomics. 2007; 4: 25-37. http://dx.doi.org/10.1586/ 14789450.4.1.25

[18] ZUBEROVIC A, WETTERHALL M, HANRIEDER J, BERGQUIST J. CE MALDI-TOF/TOF MS for multiplexed quantification of proteins in human ventricular cerebrospinal fluid. Electrophoresis. 2009; 30: 1836-43. http://dx.doi. org/10.1002/elps.200800714

[19] TREMOSINI S, FORNER A, BOIX L, VILANA R, BIANCHI $\mathrm{L}$, et al. Prospective validation of an immunohistochemical panel (glypican 3, heat shock protein 70 and glutamine synthetase) in liver biopsies for diagnosis of very early hepatocellular carcinoma. Gut. 2012; 61:1481-7. http://dx.doi. org/10.1136/gutinl-2011-301862

[20] MATHEWS ST, PLAISANCE EP, KIM T. Imaging systems for westerns: chemiluminescence vs. infrared detection. Methods Mol Biol. 2009; 536: 499-513. http://dx.doi.org/10.1007/9781-59745-542-8 51

[21] HUANG HL, STASYK T, MORANDELL S, DIEPLINGER H, FALKENSAMMER G, et al. Biomarker discovery in breast cancer serum using 2-D differential gel electrophoresis/ MALDI-TOF/TOF and data validation by routine clinical assays. Electrophoresis. 2006; 27: 1641-50. http://dx.doi. org/10.1002/elps.200500857

[22] CHONG PK, GAN CS, PHAM TK, WRIGHT PC. Isobaric tags for relative and absolute quantitation (iTRAQ) reproducibility: Implication of multiple injections. J Proteome Res. 2006; 5: 1232-40. http://dx.doi.org/10.1021/pr060018u

[23] ZHANG F, CHEN JY. Discovery of pathway biomarkers from coupled proteomics and systems biology methods. BMC genomics. 2010; 11 Suppl 2: S12. http://dx.doi.org/10.1186/ 1471-2164-11-S2-S12

[24] LIN ZY, CHUANG WL, CHUANG YH. Amphotericin B up-regulates angiogenic genes in hepatocellular carcinoma cell lines. European journal of clinical investigation. 2009; 39: 239-45. http://dx.doi.org/10.1111/j.1365-2362.2008.02066. $\mathrm{x}$

[25] SCHWARZBAUER JE, DESIMONE DW. Fibronectins, their fibrillogenesis, and in vivo functions. Cold Spring Harb Perspect Biol. 2011; 3. 26 Wang F, Song G, Liu M, Li X, Tang H. miRNA-1 targets fibronectin1 and suppresses the migration and invasion of the HEp2 laryngeal squamous carcinoma cell line. FEBS letters. 2011; 585: 3263-9. http://dx.doi.org/ 10.1016/j.febslet.2011.08.052

[27] ZHAO J, ZHAI W, ZHANG Y. [Expression of integrin alpha 5 , beta 1 subunit and fibronectin mRNAs in human hepatocellular carcinoma]. Zhonghua Bing Li Xue Za Zhi.1998; 27: 94-8.

[28] MOTTA G, ROJKJAER R, HASAN AA, CINES DB, SCHMAIER AH. High molecular weight kininogen regulates prekallikrein assembly and activation on endothelial cells: a novel mechanism for contact activation. Blood. 1998; 91: 516-28.

[29] RITHIDECH KN, HONIKEL L, RIEGER R, XIE W, FISCHER $\mathrm{T}$, et al. Protein-expression profiles in mouse blood-plasma following acute whole-body exposure to (137)Cs gamma rays. International journal of radiation biology. 2009; 85: 432-47. http://dx.doi.org/10.1080/09553000902820390 
[30] LINDEN M, LIND SB, MAYRHOFER C, SEGERSTEN U, WESTER K, et al. Proteomic analysis of urinary biomarker candidates for nonmuscle invasive bladder cancer. Proteomics. 2012; 12: 135-44. http://dx.doi.org/10.1002/ pmic. 201000810

[31] SANDANAYAKE NS, SINCLAIR J, ANDREOLA F, CHAPMAN MH, XUE A, et al. A combination of serum leucine-rich alpha-2-glycoprotein 1, CA19-9 and interleukin-6 differentiate biliary tract cancer from benign biliary strictures. Br J Cancer. 2011; 105: 1370-8. http://dx.doi. org/10.1038/bjc.2011.376

[32] POON IK, PATEL KK, DAVIS DS, PARISH CR, HULETT MD. Histidine-rich glycoprotein: the Swiss Army knife of mammalian plasma. Blood. 2011; 117: 2093-101. http:// dx.doi.org/10.1182/blood-2010-09-303842

[33] ROLNY C, MAZZONE M, TUGUES S, LAOUI D, JOHANSSON I, et al. HRG inhibits tumor growth and metastasis by inducing macrophage polarization and vessel normalization through downregulation of PlGF. Cancer Cell. 2011; 19: 31-44. http://dx.doi.org/10.1016/j.ccr.2010.11.009

[34] YOSHIOKA T, NISHIKAWA Y, ITO R, KAWAMATA M, DOI Y, et al. Significance of integrin alphavbeta5 and erbB3 in enhanced cell migration and liver metastasis of colon carcinomas stimulated by hepatocyte-derived heregulin. Cancer Sci. 2010; 101: 2011-8. http://dx.doi.org/10.1111/j.13497006.2010.01640.x

[35] LIU Y, HE J, LI C, BENITEZ R, FU S, et al. Identification and confirmation of biomarkers using an integrated platform for quantitative analysis of glycoproteins and their glycosylations. J Proteome Res. 2010; 9: 798-805. http://dx.doi.org/10.1021/ pr900715p

[36] HU RH, LEE PH, YU SC. Secretion of acute-phase proteins before and after hepatocellular carcinoma resection. J Formos Med Assoc. 1999; 98: 85-91.

[37] SIEGHART W, PINTER M, HUCKE F, GRAZIADEI I, SCHONIGER-HEKELE M, et al. A single determination of C-reactive protein at the time of diagnosis predicts long term outcome of patients with hepatocellular carcinoma. Hepatology. 2012.

[38] GUTFELD O, PRUS D, ACKERMAN Z, DISHON S, LINKE RP, et al. Expression of serum amyloid A, in normal, dysplastic, and neoplastic human colonic mucosa: implication for a role in colonic tumorigenesis. J Histochem Cytochem. 2006; 54: 63-73. http://dx.doi.org/10.1369/jhc.5A6645.2005
[39] SHU H, KANG X, GUO K, LI S, LI M, et al. Diagnostic value of serum haptoglobin protein as hepatocellular carcinoma candidate marker complementary to alpha fetoprotein. Oncol Rep. 2010; 24: 1271-6.

[40] AZUMA T, KOTHS K, FLANAGAN L, KWIATKOWSKI D. Gelsolin in complex with phosphatidylinositol 4,5-bisphosphate inhibits caspase- 3 and -9 to retard apoptotic progression. J Biol Chem. 2000; 275: 3761-6. http://dx.doi.org/10.1074/ jbc.275.6.3761

[41] AN JH, KIM JW, JANG SM, KIM CH, KANG EJ, et al. Gelsolin negatively regulates the activity of tumor suppressor p53 through their physical interaction in hepatocarcinoma HepG2 cells. Biochem Biophys Res Commun. 2011; 412: 44-9. http://dx.doi.org/10.1016/j.bbrc.2011.07.034

[42] GUR-DEDEOGLU B, KONU O, BOZKURT B, ERGUL $\mathrm{G}$, SECKIN S, et al. Identification of endogenous reference genes for qRT-PCR analysis in normal matched breast tumor tissues. Oncol Res. 2009; 17: 353-65. http://dx.doi. org/10.3727/096504009788428460

[43] BROCK R, XIONG B, LI L, VANBOGELEN RA, CHRISTMAN L. A multiplex serum protein assay for determining the probability of colorectal cancer. Am J Cancer Res. 2012; 2: 598-605.

[44] KLOTH JN, GORTER A, FLEUREN GJ, OOSTING J, ULJEE $S$, et al. Elevated expression of SerpinA1 and SerpinA3 in HLA-positive cervical carcinoma. J Pathol. 2008; 215: 222-30. http://dx.doi.org/10.1002/path.2347

[45] WHITESIDE TL, FERRONE S. For breast cancer prognosis, immunoglobulin kappa chain surfaces to the top. Clin Cancer Res. 2012; 18: 2417-9. http://dx.doi.org/10.1158/1078-0432. CCR-12-0566

[46] LEE C, BONGCAM-RUDLOFF E, SOLLNER C, JAHNENDECHENT W, CLAESSON-WELSH L. Type 3 cystatins; fetuins, kininogen and histidine-rich glycoprotein. Front Biosci. 2009; 14: 2911-22. http://dx.doi.org/10.2741/3422

[47] HAMM A, VEECK J, BEKTAS N, WILD PJ, HARTMANN A, et al. Frequent expression loss of Inter-alpha-trypsin inhibitor heavy chain (ITIH) genes in multiple human solid tumors: a systematic expression analysis. BMC Cancer. 2008; 8: 25. http://dx.doi.org/10.1186/1471-2407-8-25

[48] CHONG P.K, LEE H, ZHOU J, LIU SC, LOH MC, et al. ITIH3 is a potential biomarker for early detection of gastric cancer. J Proteome Res. 2010; 9: 3671-9. http://dx.doi.org/10.1021/ pr100192h 